\title{
Quality assessment of soaps produced from bleached palm oil and Moringa oleifera seed oil
}

\section{Idoko Owoicho*}

Chemistry Advanced Research Center, Sheda Science and Technology Complex, PMB 186, Garki, Abuja, Nigeria.

Global Journal of Engineering and Technology Advances, 2021, 07(01), 001-005

Publication history: Received on 24 February 2021; revised on 30 March 2021; accepted on 02 April 2021

Article DOI: https://doi.org/10.30574/gjeta.2021.7.1.0048

\begin{abstract}
Soap is sodium or potassium salt of fatty acid produced by saponification reaction using sodium or potassium hydroxide. It is used for cleaning, bathing, and washing. Soaps were produced from bleached palm oil (BPO) and Moringa oleifera seed oil using the cold process method with slight modification. The physicochemical properties (acid value, saponification value, peroxide value, iodine value and moisture content) of the oil were determined and it showed that the values are within the standard specifications. The quality of the soaps were also assessed by determining the physicochemical properties such as; free caustic alkali, matter insoluble in alcohol (MIA), pH, total fatty matter (TFM), cleaning properties, washing properties and foam stability. All the results obtained showed that the soaps analyzed are good soaps safe for the skin.
\end{abstract}

Keywords: Bleached palm oil; Moringa oleifera seed oil; Physicochemical properties; Soap

\section{Introduction}

Soap is sodium or potassium salt of fatty acid produced by saponification reaction using sodium or potassium hydroxide. In ancient Babylon, date back to around 2800BC, soap was prepared by heating animal fat or oil with wood ashes. Wood ashes contain potassium carbonate and sodium carbonate which make the solution basic (Woollatt, 1985). The modern commercial method of making soap involves boiling fats or oils in aqueous sodium hydroxide or potassium hydroxide and adding sodium chloride or potassium chloride to precipitate the soaps respectively. The soap is then dried and pressed into bars. Perfumes can be added for scented soaps, dyes can be added for coloured soaps, sand can be added for scouring soaps, and air can be blown into the soaps to make it float (Ossai, 2014). In other words, soap making involves the hydrolysis of triglycerides as shown in Scheme 1

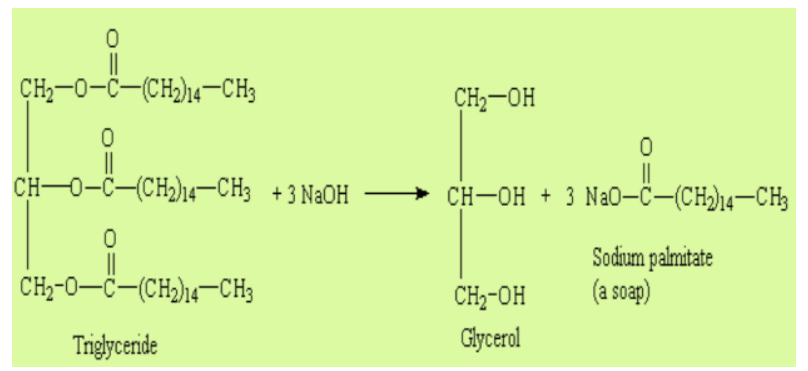

Scheme 1 Hydrolysis of triglycerides (fat)

\footnotetext{
* Corresponding author: Idoko Owoicho Phone no. 07068688448; Email: samuelidoko2015@yahoo.com

Chemistry Advanced Research Center, Sheda Science and Technology Complex, PMB 186, Garki, Abuja, Nigeria. 
Based on its chemical properties as an anionic surface active agent (surfactant), soap is used to clean and wash skin and clothing (Woollatt, 1985). The fatty acids, stearic, palmitic, myristic, lauric and oleic acids, contribute to lathering and washing properties of the soaps (Ossai, 2014). The chemical characteristics of soap depend on several factors: the strength and purity of alkali, the kind of oil used, completeness of saponification and age of the soap. Such chemical characteristics include moisture content, total fatty acids (TFM), pH, free alkali, and percent chloride (Butler, 1987).

Palm oil has been widely used as fatty raw material in the manufacture of soap Nangbes et al., 2009, but the bleached palm oil is more preferable because of its high saponification value compared to the crude palm oil.

The seeds of Moringa oleifera seed contain up to $40 \%$ of oil by weight which is used for cooking, soap manufacture, cosmetic base and in lamps.

Most soap manufacturers add other additives which are not environmentally friendly to soap probably to improve on a certain qualities of the soaps. This work involves producing soaps without adding any additives and comparing it with other conventional soaps.

\section{Material and methods}

The Moringa oleifera seed oil was extracted using n-Hexane, while the bleached palm oil was gotten from a crude palm oil obtained from a market in Gwagwalada Area Council, Abuja. The other chemicals used were of Analar grade.

\subsection{Bleaching of Oil}

In $250 \mathrm{ml}$ beaker, $200 \mathrm{ml}$ of the oil sample was heated to $1300 \mathrm{C}, 20 \mathrm{~g}$ of activated carbon was added while heating the contents of the beaker to $1500 \mathrm{C}$. The mixture was stirred manually during the heating and the mixture was then filtered (James, 2007).

\subsection{Physicochemical Properties and Analysis}

The saponification value, unsaponifiable matter, acid value, iodine value, peroxide value, volatile matter and refractive index were determined using methods described by Olokodana, 2003.

\subsection{Free Caustic Alkali}

Free caustic alkali was determined by the method described by Onyango et al., 2014. According to these method 5 grams of finished soap was weighed and dissolved in $30 \mathrm{~mL}$ of ethanol. Few drops of phenolphthalein indicator and 10 $\mathrm{mL}$ of $20 \% \mathrm{BaCl} 2$ were added. The resulting solution was then titrated against $0.05 \mathrm{M} \mathrm{H} 2 \mathrm{SO}$ (aq). The volume of the acid obtained was calculated using equ. 1

Where; VA is the Volume of acid, W is the Weight of soap and FCA is the Free caustic alkali

\subsection{Matter Insoluble in Alcohol}

Five grams of soap sample was dissolved in $50 \mathrm{ml}$ hot ethanol and quantitatively transferred in a pre-weighed filter paper. The residue was dried in the oven at $105^{\circ} \mathrm{C}$ for 30 minutes, cooled and weighed again then reading taken. The calculation of matter insoluble in alcohol (MIA) was carried out using equ. 2 (Ossai, 2014).

Where: Ws is the Weight of sample + filter paper, FP is the Weight of filter paper and W is the Weight of the sample (Ogunsuyi and Akinnawo, 2012).

\subsection{Determination of $\mathbf{p H}$}

$2 \mathrm{~g}$ of soaps were added into $20 \mathrm{ml}$ distilled water and shaken and the soap suspensions were allowed to stay for at least 12 hours before the $\mathrm{pH}$ meter was inserted into a beaker containing the various soap suspensions, and the readings were recorded (Ossai, 2014).

\subsection{Determination of Free Fatty Matter}

The total free fatty matter (FFM) was obtained using equ. 3

Where: MC is the Moisture content and MIA is the Matter insoluble in alcohol (Ossai, 2014). 


\subsection{Moisture/Volatile Matter}

For the determination of moisture content, 5 grams of samples was accurately weighed using analytical balance of sensitivity $0.1 \mathrm{mg}$ into dried tarred moisture dish in an oven for $2 \mathrm{hrs}$ and temperature of $101^{\circ} \mathrm{C}$ and repeated until a constant weight was reached. The \% moisture was calculated using equ. 4 (Chatterjee and Pakrashi, 1994).

Where; CW is the Weight of crucible, CS is the Weight of crucible + sample, and CL is the Weight of crucible + sample after floating (Ogunsuyi and Akinnawo, 2012).

\subsection{Washing Properties}

A small amount of the dry soap was used to wash the hand using deionized water. The lathering properties and the "feel" of the soap was taken (very slippery, greasy, or about normal) (Coulibaly et al., 2009).

\subsection{Foam Stability}

$1 \%$ of the soap samples were prepared and equal amount of the soap solution was measured into test tubes. The solution was shaken vigorously for $1 \mathrm{~min}$ and allowed to stand for five minutes. The height of the foam was observed and recorded (Coulibaly et al., 2009).

\subsection{Cleaning Properties}

A drop of used oil was placed on strips of filter paper. The strips was placed into test tubes containing the $1 \%$ soap solutions. The soap solutions was then shaken vigorously and allowed to stay for 2 mins. The filter paper was removed and rinsed with water. The cleansing power was observed and recorded (Coulibaly et al., 2009).

\subsection{Soap Preparation (cold process)}

The soaps were produced using the cold process with slight modification. The appropriate amount of the oils were weighed and melted and mixed with $20 \%$ of $\mathrm{NaOH}$ in a beaker. After stirring for 30 mins, it was poured into a mould and allowed to cure. It was removed from the mould after solidifying.

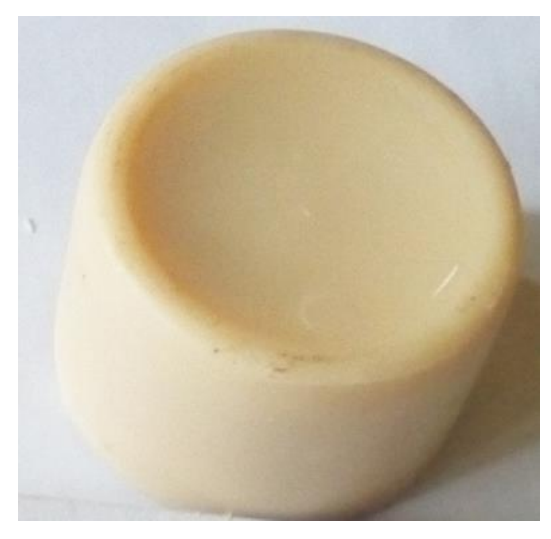

Figure 1 (a) Bleached palm oil (BPO) soap (b) Moringa oil soap

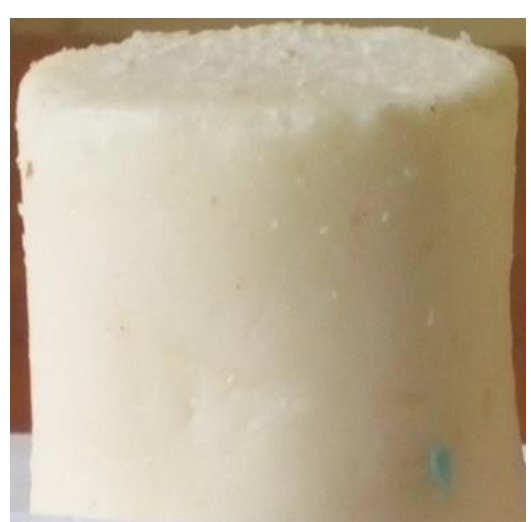

\section{Results and discussion}

Table 1 Physicochemical Properties of bleached palm oil, Moringa oleifera seed oil

\begin{tabular}{|l|l|l|l|l|l|}
\hline $\begin{array}{l}\text { Oils } \\
\text { Samples }\end{array}$ & $\begin{array}{l}\text { SAP. V. } \\
\text { mgKOH/g }\end{array}$ & $\begin{array}{l}\text { IODINE V. } \\
\text { WIJS }\end{array}$ & $\begin{array}{l}\text { PEROXIDE V. } \\
\text { meq/kg }\end{array}$ & $\begin{array}{l}\text { ACID V. } \\
\text { mgKOH/g }\end{array}$ & $\begin{array}{l}\text { M. C. } \\
\text { \% }\end{array}$ \\
\hline Bpo & 206.55 & 57.82 & 5.02 & 5.02 & 0.02 \\
\hline Moringa & 180 & 80.98 & 4.02 & 4.29 & 0.14 \\
\hline Codex & - & - & $10-15$ max & 8.0 & 0.2 \\
\hline
\end{tabular}


Table 2 Physicochemical properties of the soap samples

\begin{tabular}{|l|l|l|l|l|l|}
\hline Soap Samples & pH & Free Alkali \% & MIA \% & TFM \% & Moisture content \% \\
\hline Bpo & 10.07 & 0.08 & 35 & 56.80 & 8.26 \\
\hline Moringa & 10.02 & 0.16 & 38 & 55.95 & 6.65 \\
\hline Standard Specifications & $7-10$ & $2-5 \%$ & $70 \mathrm{Max}$ & $50-100 \%$ & $10-14 \%$ \\
\hline
\end{tabular}

Table 3 Other physical parameters of the soaps samples

\begin{tabular}{|l|l|l|l|}
\hline Soap Samples & Cleaning properties & Washing properties & Foam stability \\
\hline Bpo & Very good & Normal & Very stable \\
\hline Moringa & Very Good & Normal & Stable \\
\hline
\end{tabular}

The physicochemical properties of the oils were presented in Table 1. The saponification values of BPO and Moringa oils is $206.55 \mathrm{mgKOH} / \mathrm{g}$ and $180 \mathrm{mgKOH} / \mathrm{g}$ respectively. The high saponification values is an indication that the oils are good for soap making (Udensi and Iroegbu, 2007). The iodine value for Moringa oil is higher than that of the BPO. The iodine is the measure of the level of unsaturation of the oil, so Moringa oil will remain liquid compared to BPO at room temperature (Olokodana, 2003). The acid value of both oils fall within the standard specification of $8.00 \mathrm{mgKOH} / \mathrm{g}$. The Peroxide value is the measure of the extent of spoilage of the oil. The both oils have values that are lower than the maximum standard specification, and this indicates that the oils are rancid (Olokodana, 2003). The moisture content of the Moringa oil is $0.14 \%$, while that of BPO is $0.02 \%$. The moisture content of the oils is also lower than the maximum standard specification (Olokodana, 2003).

The physicochemical properties of the soaps are presented in Tables 2 and 3. The pH of Moringa oil soap is 10.02 , while that of BPO is 10.07. The $\mathrm{pH}$ values falls within the range of the standard specification and it showed that the soaps will not be harsh to the skin or cloth (Ossai, 2014; Ogunsuyi and Akinnawo, 2012).The free alkali of both soaps is lower than the maximum standard specification of between 2 - 5\% (Zaidul et al., 2014). Free caustic alkali is one of the parameters that determine the abrasiveness of any given soap (Onyekwere,1996). The matter insoluble in alcohol (MIA), is one of the parameters used to determine the purity of soaps (Ogunsuyi and Akinnawo, 2012). It measures the non-soap material known as builders or fillers which include sodium silicate, sodium carbonate, sodium phosphate and other ingredients like bleachers, whitening agents and fluorescing agents (Ogunsuyi and Akinnawo, 2012). The MIA values for the BPO and Moringa oil soaps is 35\% and 38\% respectively and these are lower than the maximum standard specification of $70 \%$. This could be due to the fact that the soaps produced do not contain any additives. The total fatty matter (TFM) of the soaps as presented in Table 1 showed that the values fall within the standard specification of 50 $100 \%$. TFM is the parameter used to describe the quality of a soap (Idoko et al., 2018). The moisture content of the soaps are lower than the maximum standard specification, which shows that the shelf life of the soaps will be high (Idoko et al., 2018).

The other physical parameters analyzed such as cleaning, washing and foam properties in Table 3 showed that the cleaning properties of Moringa oil and BPO very good, their washing properties are normal, while foam stability of BPO is more stable than that of Moringa oil soap

\section{Conclusion}

At the end of this work, soaps were produced from bleached palm oil and Moringa oleifera seed oil. The physicochemical properties of the soaps were also analyzed. The two soaps meet the standard specifications for a good soap and they are both skin friendly. 


\section{Compliance with ethical standards}

\section{Acknowledgments}

I will to acknowledge the efforts of my employer for given the opportunity to carry out the research work in the Chemistry Advanced Research Center, SHESTCO, Abuja, Nigeria.

\section{Disclosure of conflict of interest}

No conflict of interest, only one author is involved.

\section{References}

[1] Assessment of the Physicochemical Properties of Selected Commercial Soaps Manufactured and Sold in Kenya. Open Journal of Applied Sciences. 4: 433-440.

[2] Boadu KO, Anang, MA, Kyei SK. Chemical characterization of shea butter oil soap (Butyrospermum parkii G. Don). International Journal of Development and Sustainability. 2017; 6(10): 1282-1292.

[3] Butler H. Pounchers Perfumes, Cosmetics and Soaps vol. 39th edition. Blackier Academics and Professional, London. 1987; 393-395, 451-452, 454-457, 464-468 and 481-82.

[4] Chatterjee A. and Pakrashi S. The Treatise on Indian Medicinal Plants. Publications and Coulibaly Y., Ouedraogo S. and Niculescu N. (2009). Experimental Study of Shea butter Extraction Efficiency using a Centrifugal Process. ARPN Journal of Engineering and Applied Sciences. 1994; 4(6): 14-19.

[5] Directorate, New Delhi. 3(73).

[6] Idoko O, Emmanuel SA, Salau AA and Obigwa PA. Quality assessment on some soaps sold in nigeria. Nigerian Journal of Technology (NIJOTECH). 2018; 37(4): 1137 - 1140.

[7] James 00. Bleaching performance of Nigerian (Yola) bentonite. Latin American Applied Research. 2007.

[8] Nangbes JG, Zukdimma A, Wufem BM, Lawam TD and Dawam NN. Quality Survey and Safety of Some Toilet Soaps in the Nigerian Market: A Case Study of B/Ladi, Bokkos and Pankshin, Plateau State. IOSR Journal of Applied Chemistry (IOSR-JAC). 7(7): 29-35.

[9] Ogunsuyi HO and Akinnawo CA. Quality Assessment of Soaps Produced from Palm Bunch Ash-Derived Alkali and Coconut Oil. J. Appl. Sci. Environ. Manage. 2012; 16(4): 363-366.

[10] Olokodana FA. Analysis of fats and oils: 2 day mandatory workshop on sample preparation for the analysis of food raw and processed, 3rd - 4th December, 2003; Lagos Institute of Public Analysts of Nigeria (IPAN). 2003; 17-44.

[11] Onyango P., Vivian O., Nathan AO., Linda M., Wesley NO. Assessment of the physicochemical properties of selected commercial soaps manufactured and sold in Kenya. Open Journal of Applied Sciences, 2014; 4: 433-440

[12] Onyekwere C. Cassava Peels Ash: An Alternative Source of Alkali in Soap Production. BEng Thesis, Department of Chemical Engineering, University of Port-Harcourt, Port-Harcourt. 1996; 1-33.

[13] Ossai EK. Preparation and Characterization of Metal Soaps of Cocos Nucifera Seed Oil . Appl. Sci. Environ. Manage. 2014; 18(2): 359-363.

[14] Udensi FA. and Iroebgu FC. Quality assessment of palm oil sold in major markets in Abia state, Nigeria. AgroScience. 2007; 6(2).

[15] Woollatt E. The Manufacturer of Soaps Other Detergents and Glycerin, 1st Edition, Ellis Hardwood Ltd, West Sessux, England. 1985; 34-35, 47-55, 267 and 284.

[16] Zaidul ISM, Norulaini NNA, Sahena F and Jaffri JM. Supercritical carbon dioxide extraction and studies of mango seed kernel for cocoa butter analogy fats. CyTA - Journal of Food. 2014; 12(1): 97-103. 